\title{
Radiopharmaceuticals for SPECT Cancer Detection
}

\author{
V I Chernov ${ }^{1,2}$, A A Medvedeva ${ }^{1,2}$, R V Zelchan ${ }^{1,2}$, I G Sinilkin ${ }^{1,2,}$ E S Stasyuk ${ }^{2}$, \\ L A Larionova ${ }^{2}$, E M Slonimskaya ${ }^{1}$, E L Choynzonov ${ }^{1}$ \\ ${ }^{1}$ Tomsk Cancer Research Institute, Tomsk, Russia \\ ${ }^{2}$ National Research Tomsk Polytechnic University, Tomsk, Russia \\ E-mail: chernov@oncology.tomsk.ru
}

\begin{abstract}
The purpose of the study was to assess the efficacy of single photon emission computed tomography (SPECT) with ${ }^{199} \mathrm{Tl}$ and ${ }^{99 \mathrm{~m}} \mathrm{Tc}-\mathrm{MIBI}$ in the detection of breast, laryngeal and hypopharyngeal cancers. Materials and Methods: a total of 220 patients were included into the study. Of them, there were 120 patients with breast lesions (100 patients with breast cancer and 20 patients with benign breast tumors) and 100 patients with laryngeal/hypopharyngeal diseases (80 patients with laryngeal/hypopharyngeal cancer and 20 patients with benign laryngeal/hypopharyngeal lesions). Results: no abnormal ${ }^{199} \mathrm{Tl}$ uptake was seen in all patients with benign breast and laryngeal lesions, indicating a $100 \%$ specificity of ${ }^{199} \mathrm{Tl}$ SPECT. In breast cancer patients, increased ${ }^{199} \mathrm{Tl}$ uptake in the breast was visualized in $94.8 \%$ patients, ${ }^{99 \mathrm{~m}} \mathrm{Tc}-\mathrm{MIBI}$ in $93.4 \%$ patients. Increased ${ }^{199} \mathrm{Tl}$ uptake in axillary lymph nodes was detected in $60 \%$ patients and ${ }^{99 \mathrm{~m}} \mathrm{Tc}-\mathrm{MIBI}$ in $93.1 \%$ patients. In patients with laryngeal/hypopharyngeal cancer, sensitivity of SPECT with ${ }^{199} \mathrm{Tl}$ and ${ }^{99 \mathrm{~m}} \mathrm{Tc}-\mathrm{MIBI}$ were $95 \%$. The ${ }^{199} \mathrm{Tl}$ SPECT sensitivity in identification of regional lymph node metastases in patients with laryngeal/hypopharyngeal cancer was $75 \%$ and the ${ }^{99 \mathrm{~m}}$ Tc-MIBI SPECT sensitivity was $17 \%$. Conclusion: the data obtained show that SPECT with ${ }^{199} \mathrm{Tl}$ and ${ }^{99 \mathrm{~m}} \mathrm{Tc}-\mathrm{MIBI}$ can be used as one of the additional imaging methods in detection of tumors.
\end{abstract}

\section{Introduction}

According to recent WHO data, more than 10 million newly diagnosed cancer cases occur annually in the world. In many countries, cancer ranks the second most common cause of death following cardiovascular diseases [1].

Nuclear medicine techniques have the advantage over X-ray or magnetic resonance imaging in terms of higher specificity with a similar high sensitivity for cancer detection $[2,3,4]$. Moreover, the use of nuclear medicine imaging in detection of laryngeal/hypopharyngeal tumors allows prevention of unnecessary diagnostic invasive procedures.

${ }^{99 \mathrm{~m}} \mathrm{Tc}$-methoxy-isobutyl-isonitrile $\left({ }^{99 \mathrm{~m}} \mathrm{Tc}-\mathrm{MIBI}\right)$ is the most widely used single photon emission computed tomography (SPECT) tracer in detecting malignant disease [5, 6[6]]. However, this tracer with a relatively high sensitivity has a rather low specificity. Therefore, the search for radiopharmaceuticals characterized by a high specificity while maintaining adequate sensitivity is of great importance.

More than 30 years ago, the diagnostic value of ${ }^{201} \mathrm{Tl}$ for detecting malignant tumors was studied. It was shown that ${ }^{201} \mathrm{Tl}$, a biological potassium analogue, actively accumulated in tumors [6[6]]. Findings from animal studies demonstrated that ${ }^{201} \mathrm{Tl}$ had higher tumor accumulation compared to other radiopharmaceuticals $[8,9[9]]$. However, a long half-life (72 hours) of ${ }^{201} \mathrm{Tl}$ limited its widespread use, 
since there was a risk of increased radiation dose to the patient's body and critical organs, especially during re-examinations, for example during chemotherapy.

It is proposed that ${ }^{199} \mathrm{Tl}$ is a more promising isotope than ${ }^{201} \mathrm{Tl}$, which is currently used in nuclear medicine. Unlike ${ }^{201} \mathrm{Tl},{ }^{199} \mathrm{Tl}$ has a more simple and cheaper production method. There are many reports on the use of this isotope for myocardial perfusion scintigraphy. Cellular uptake mechanism of ${ }^{199} \mathrm{Tl}$ is the same as that of ${ }^{201} \mathrm{Tl}$. However, because of its short half-life (7.4 hours), radiation dose to the patient's whole body and critical organs is significantly reduced. By using ${ }^{199} \mathrm{Tl}$, the radiation dose to critical organs is $4-15$ times lower than that by using ${ }^{201} \mathrm{Tl}$. It allows ${ }^{199} \mathrm{Tl}$ scintigraphy to be performed 5 times a year for the same patient $[10,11,12]$.

The aim of our study was to evaluate the efficacy of SPECT with ${ }^{199} \mathrm{Tl}$ in the detection of breast and laryngeal/hypopharyngeal carcinomas.

\section{Experiment}

A total of 220 patients were included into the study. There were 120 women with breast disease. Out of them, 39 patients with stage $\mathrm{T}_{1-4} \mathrm{~N}_{0-2} \mathrm{M}_{0}$ breast cancer and 20 patients with benign breast lesions were injected with ${ }^{199} \mathrm{Tl}$, and 61 patients with stage $\mathrm{T}_{1-4} \mathrm{~N}_{0-2} \mathrm{M}_{0}$ breast cancer were injected with ${ }^{99 \mathrm{~m}} \mathrm{Tc}$ MIBI. There were 80 patients with stage $\mathrm{T}_{1-3} \mathrm{~N}_{0-2} \mathrm{M}_{0}$ laryngeal and hypopharyngeal cancers (including 20 patients with recurrent laryngeal/hypopharyngeal cancer) and 20 patients with benign diseases, among them, 50 patients were injected with ${ }^{199} \mathrm{Tl}$ and the other 50 patients were injected with ${ }^{99 \mathrm{~m}} \mathrm{Tc}$ MIBI. None of the patients at the time of the survey showed evidence of distant metastasis.

Besides conventional imaging methods such as computed tomography, ultrasound, fibrolaryngoscopy and biopsy, all patients underwent preoperative SPECT with ${ }^{199} \mathrm{Tl}$ or ${ }^{99 \mathrm{~m}} \mathrm{Tc}-\mathrm{MIBI}$. The patients were subsequently operated on and surgical specimens were examined histologically and immunohistochemically. Patients with benign breast lesions underwent sectoral resection of the breast with subsequent histological examination.

Single photon emission computed tomography was performed using a double-head gamma-camera (E.CAM 180, Siemens) equipped with parallel high energy collimators for ${ }^{199} \mathrm{Tl}$ and parallel low energy collimators for ${ }^{99 \mathrm{~m}} \mathrm{Tc}-\mathrm{MIBI}$. The injection of ${ }^{199} \mathrm{Tl}$ at the dose of $260 \mathrm{MBq}$ or ${ }^{99 \mathrm{~m}} \mathrm{Tc}-\mathrm{MIBI}$ at the dose of $740 \mathrm{MBq}$ was made intravenously. In patients with breast disease, injection was made into the antecubital vein contralaterally to the breast lesion or in the pedal vein. Images of the breast were obtained with the patients lying in the supine position with the arms raised over the head and with the chest, both breasts, axilla and the myocardium, included into the field of view. For obtaining SPECT images in patients with laryngeal/hypopharyngeal cancer, patients were also placed in a supine position, and the detector's field of the view encompassed the head and neck region and trachea to the bifurcation. A total of 32 projection images were recorded into a $64 \times 64$ matrix (30 seconds per projection), without magnification factor. The scan images were analyzed using the manufacturer software (e.soft, Siemens, Germany). Three-dimensional images of the chest, sagittal, transverse and coronal sections were obtained. Single photon emission computed tomography scans were visually assessed. Images of contralateral areas were compared and asymmetrically increased radiotracer uptake was considered pathological.

\section{Results and discussion}

Single photon emission computed tomography revealed no abnormal ${ }^{199} \mathrm{Tl}$ uptake in the chest wall and breasts of patients with benign breast lesions. Despite a small group of patients $(n=20)$, the specificity of SPECT with ${ }^{199} \mathrm{Tl}$ was $100 \%$.

In breast cancer patients, the increased ${ }^{199} \mathrm{Tl}$ uptake was visualized in $37(94.8 \%)$ of the 39 patients, of the 6 patients with tumors less than $10 \mathrm{~mm}, 4$ showed abnormal radiotracer uptake (Figure 1). In one case, a large mass detected by mammography and ultrasound appeared as a cluster of microcalcifications. Carrying out of SPECT with ${ }^{99 \mathrm{~m}} \mathrm{Tc}-\mathrm{MIBI}$ revealed abnormal formations in the projection of the mammary glands in $59(93.4 \%)$ out of 61 patients (Figure 2). Tumors greater than $10 \mathrm{~mm}$ were detected by ${ }^{199} \mathrm{Tl}$ and ${ }^{99 \mathrm{~m}} \mathrm{Tc}$-MIBI SPECT in $100 \%$ of cases. 

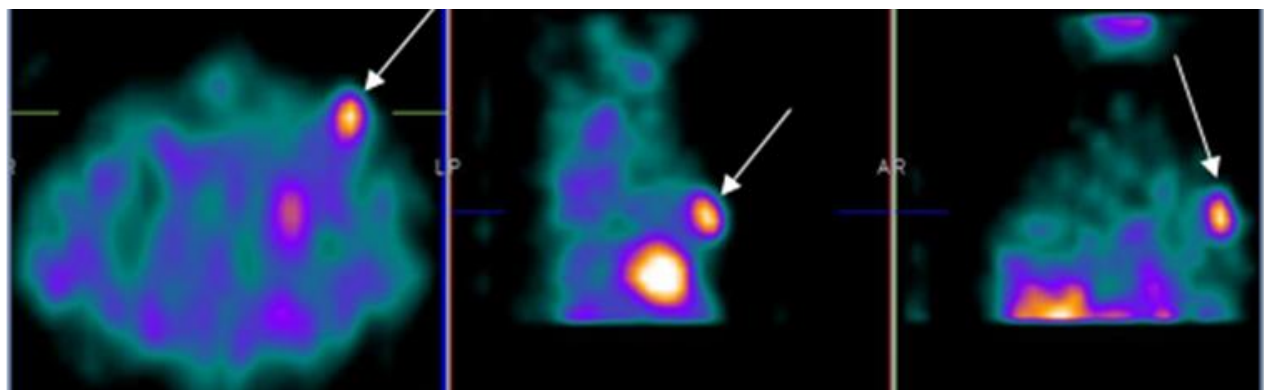

Figure 1. SPECT with ${ }^{199} \mathrm{Tl}$ for the patient with stage T2N0M0 cancer in the left breast.

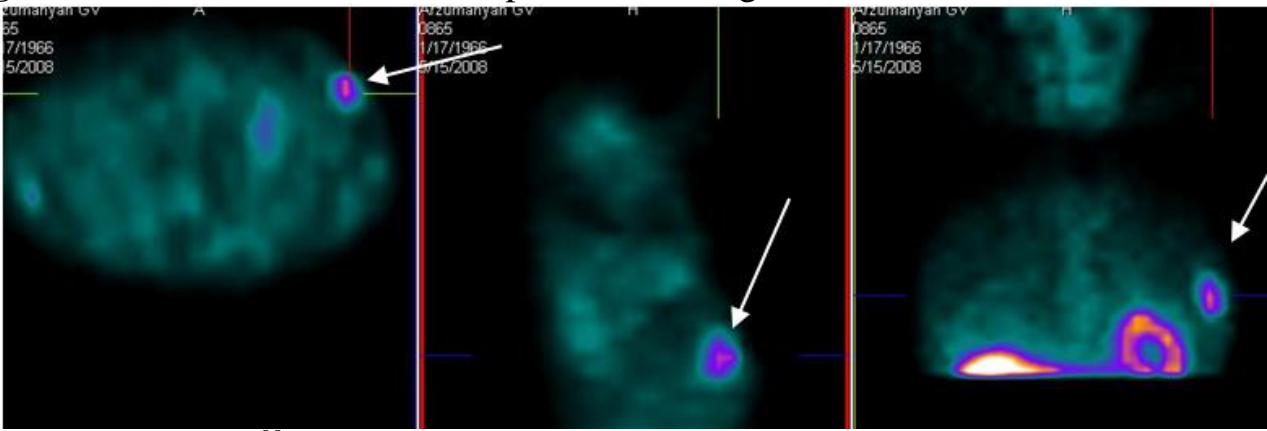

Figure 2. SPECT with ${ }^{99 \mathrm{~m}}$ Tc-MIBI for the patient with stage T1N0M0 cancer in the left breast.

It is well known that secondary infiltrative ductal breast carcinoma can be difficult to diagnose. In our study, the accuracy in differentiating malignant from benign breast lesions by SPECT with ${ }^{199} \mathrm{Tl}$ was $100 \%$, as well as with ${ }^{99 \mathrm{~m}}$ Tc-MIBI (Figures 3,4). Identification of multicentric breast cancer is an important factor in diagnosis of breast cancer. In our study, multicentric breast cancer was diagnosed in $66.6 \%$ patients during the study with ${ }^{199} \mathrm{Tl}$ and in $46.1 \%$ with ${ }^{99 \mathrm{~m}} \mathrm{Tc}-\mathrm{MIBI}$ (Figures 5,6$)$.
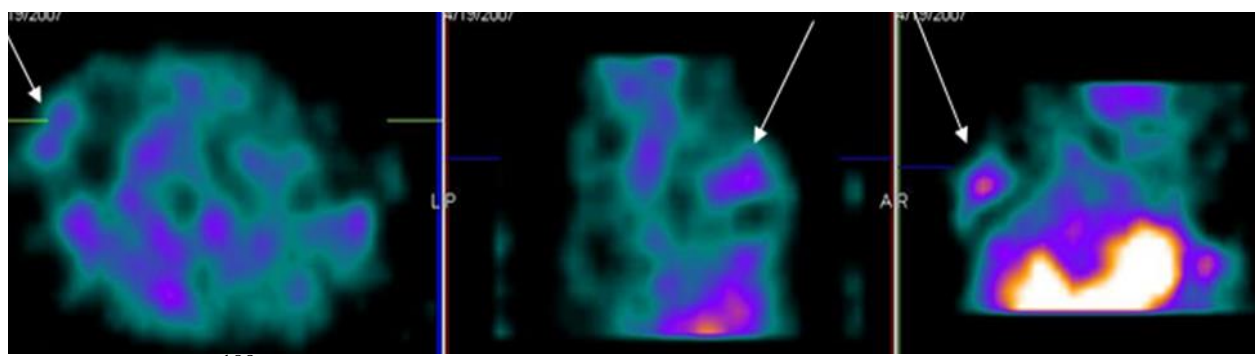

Figure 3. SPECT with ${ }^{199} \mathrm{Tl}$ for the patient with secondary infiltrative ductal breast carcinoma in the right breast.
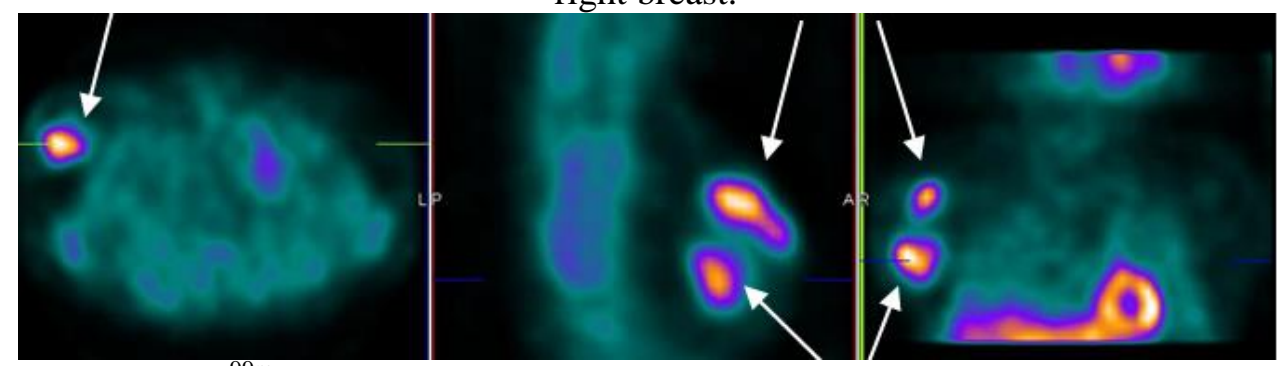

Figure 4. SPECT with ${ }^{99 \mathrm{~m}}$ Tc-MIBI for the patient with secondary infiltrative ductal breast carcinoma in the right breast. 


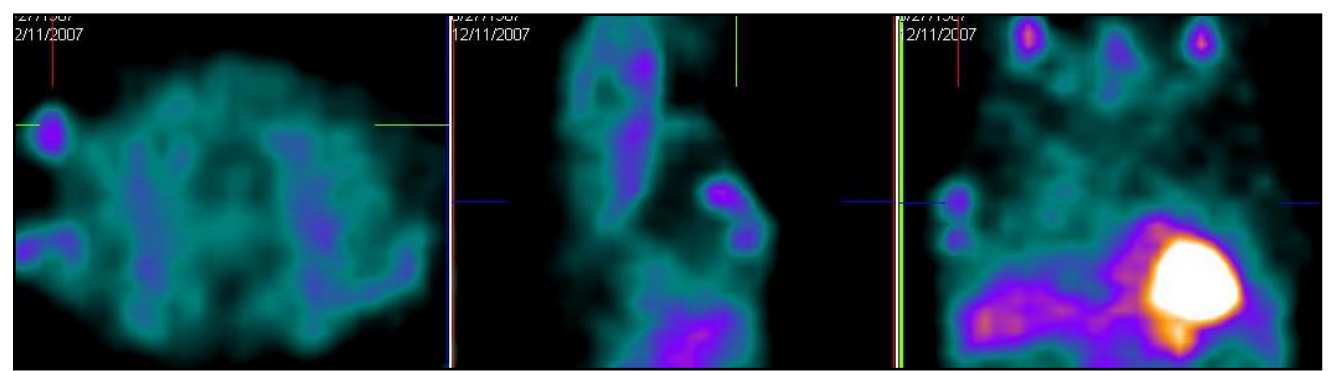

Figure 5. SPECT with ${ }^{199} \mathrm{Tl}$ for the patient with multicentric breast cancer in the right breast.
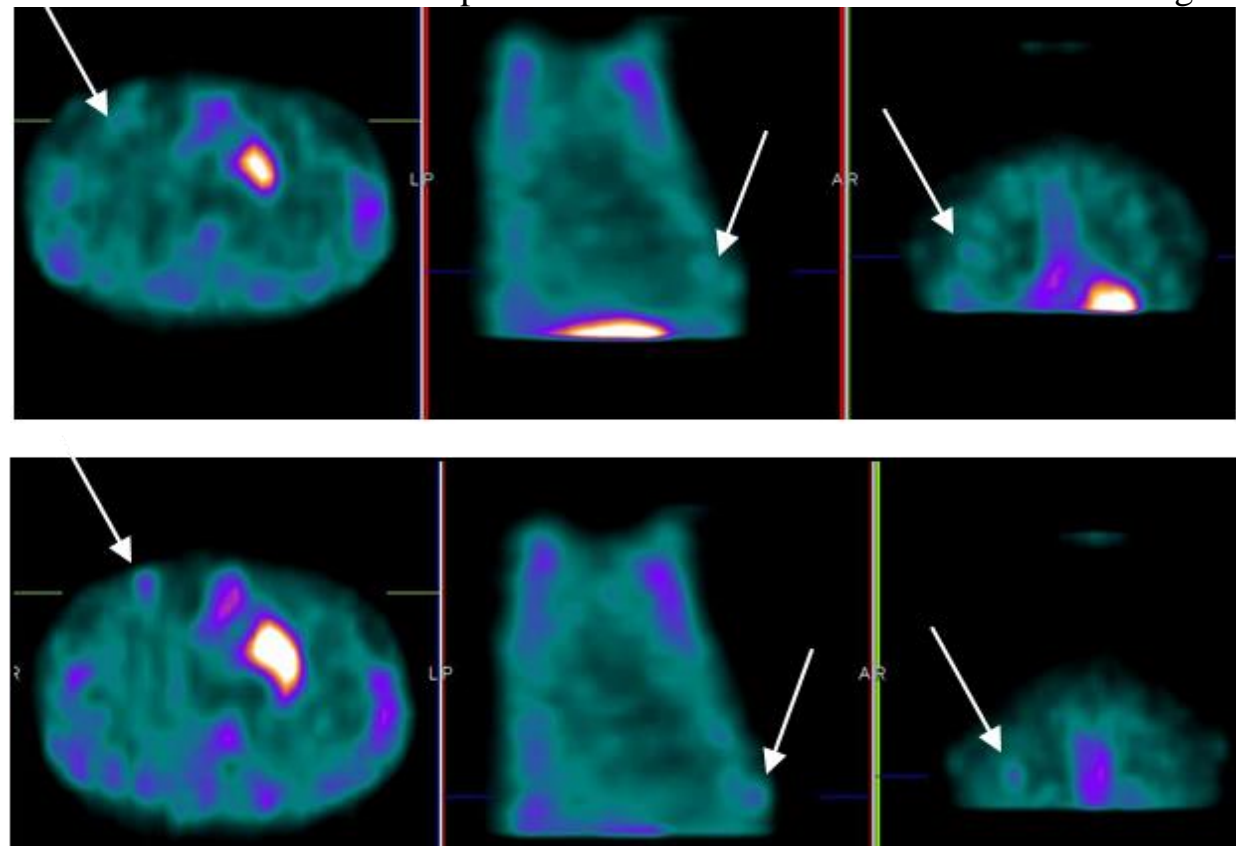

Figure 6. SPECT with ${ }^{99 \mathrm{~m}} \mathrm{Tc}-\mathrm{MIBI}$ for the patient with multicentric breast cancer in the right breast.

As regard to lymph node involvement, increased ${ }^{199} \mathrm{Tl}$ uptake in the axillary lymph nodes was observed in 15 of the 25 patients $(60 \%)$ with histologically verified metastases (Figure 7). Only 2 of the 5 patients had abnormal radiotracer uptake in the pectoral and subclavicular lymph nodes (Figure 8). Thus, the ${ }^{199} \mathrm{Tl}$ SPECT sensitivity for the detection of metastatic regional lymph nodes in breast cancer patients was $60 \%$.

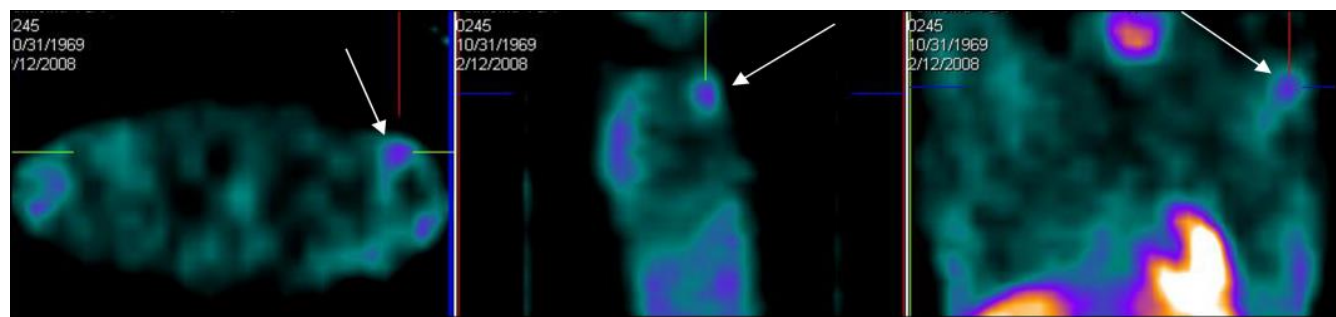

Figure 7. SPECT with ${ }^{199} \mathrm{Tl}$ in the patient with stage T2N1M0 cancer in the left breast. Axillary lymph node visualization. 

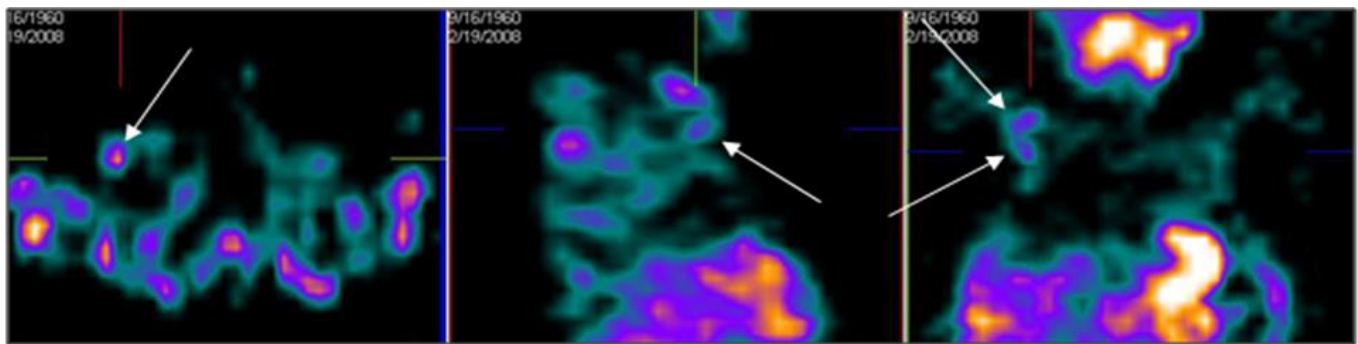

Figure 8. SPECT with ${ }^{199} \mathrm{Tl}$ in the patient with stage T2N3M0 cancer in the right breast. Visualization of pectoral and subclavicular lymph nodes.

It was possible to visualize the modified axillary lymph nodes in almost all cases during the study with ${ }^{99 m}$ Tc-MIBI: in $27(93.1 \%)$ out of 29 patients with verified metastasis pathological inclusion of the ${ }^{99 \mathrm{~m}} \mathrm{Tc}-\mathrm{MIBI}$ in axillary region was detected (Figure 9). In addition, pathological changes in the projection of pectoral lymph nodes, subclavian and subscapularis groups were detected in 5 patients. This technique allowed us to differentiate between different levels of lymph nodes (Figure 10). The sensitivity of the SPECT with ${ }^{99 m}$ Tc-MIBI in identifying metastatic regional lymph nodes was $93.1 \%$. The specificity of SPECT with ${ }^{199} \mathrm{Tl}$ was $100 \%$, with ${ }^{99 \mathrm{~m}} \mathrm{Tc}-\mathrm{MIBI}-80 \%$.
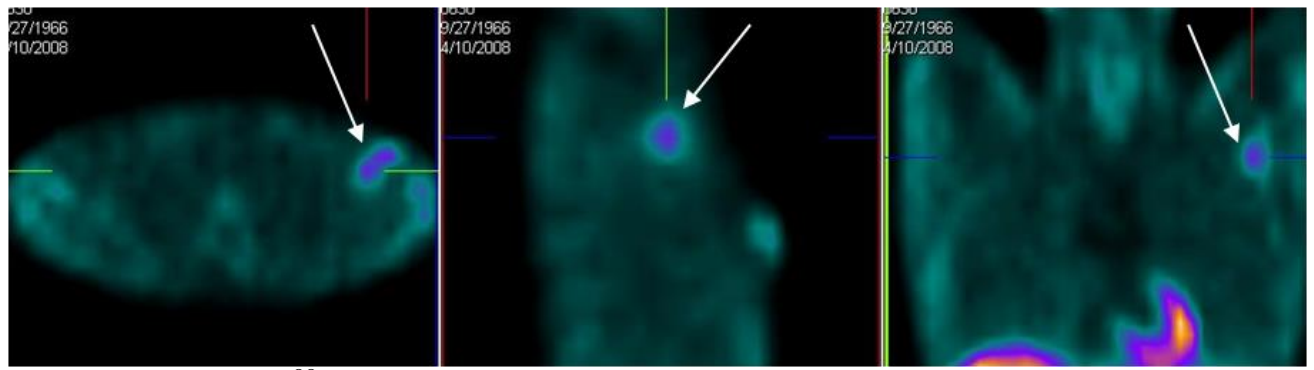

Figure 9. SPECT with ${ }^{99 \mathrm{~m}}$ Tc-MIBI in the patient with stage T2N1M0 cancer in the left breast. Axillary lymph node visualization.
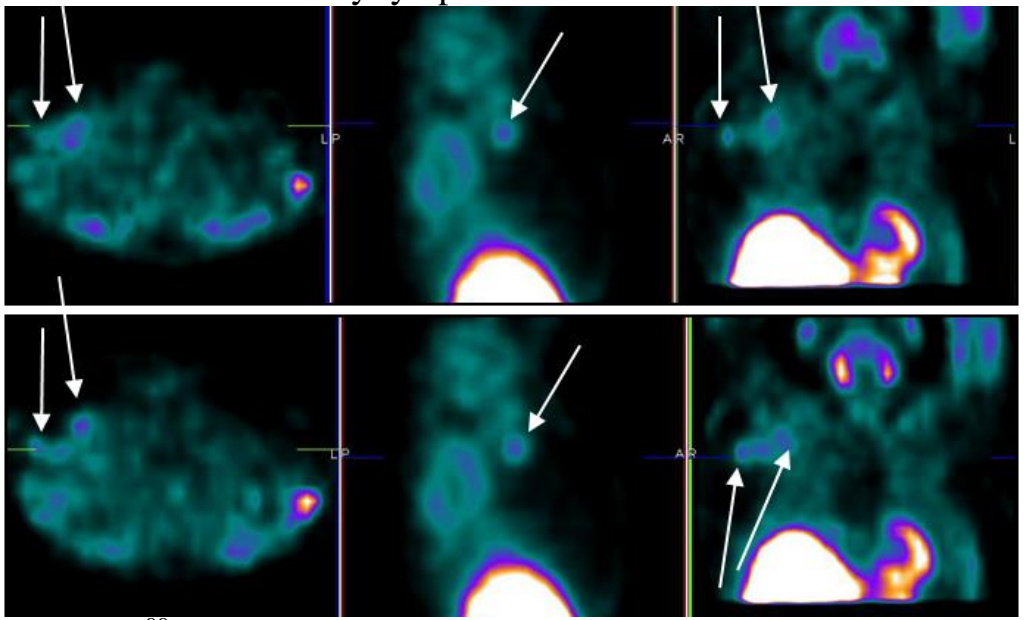

Figure 10. SPECT with ${ }^{99 \mathrm{~m}} \mathrm{Tc}-\mathrm{MIBI}$ in the patient with stage T2N3M0 cancer in the right breast. Visualization of pectoral, subclavicular lymph nodes.

In laryngeal/hypopharyngeal cancer patients, abnormal both ${ }^{199} \mathrm{Tl}$ and ${ }^{99 \mathrm{~m}} \mathrm{Tc}-\mathrm{MIBI}$ uptake was detected in $95 \%$ patients with primary laryngeal/hypopharyngeal cancer (Figures 11,12 ). It should be noted that despite limitations for SPECT in visualization of tumors less than $10 \mathrm{~mm}$. The minimum lesion size was $4 \mathrm{~mm}$ in greatest dimension. 
In 20 of the 20 patients with recurrent laryngeal/hypopharyngeal cancer was detected abnormal uptake both ${ }^{199} \mathrm{Tl}$ and ${ }^{99 \mathrm{~m}} \mathrm{Tc}-\mathrm{MIBI}$, it was $100 \%$ sensitivity of SPECT with ${ }^{199} \mathrm{Tl}$ and ${ }^{99 \mathrm{~m}} \mathrm{Tc}-\mathrm{MIBI}$ in the diagnosis of recurrent laryngeal/hypopharyngeal cancer.
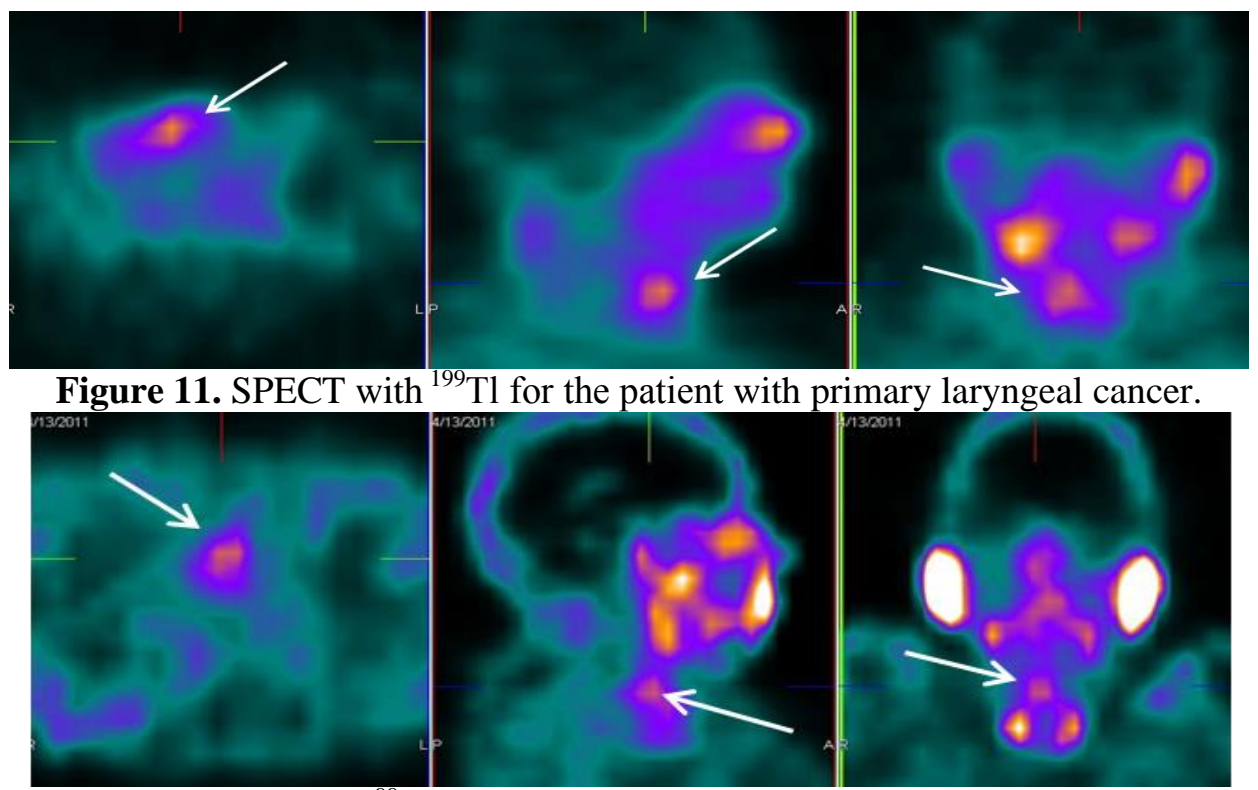

Figure 12. SPECT with ${ }^{99 \mathrm{~m}} \mathrm{Tc}-\mathrm{MIBI}$ for the patient with primary laryngeal cancer.

Histological examination of specimens obtained by ultrasound-guided fine needle aspiration biopsy showed cervical lymph node metastases in $18.3 \%$ of cases. On SPECT the lymph nodes, affected by metastases, were visualized in the form of tracer hyperfixation focus of irregular shape with rough, indistinct boundaries, expressed by a nonuniform distribution of tracer, usually of low intensity.

Single photon emission computed tomography with ${ }^{199} \mathrm{Tl}$ could detect biopsy-proven lymph node metastases in $75 \%$ of cases (Figure 13). When performing SPECT with ${ }^{99 \mathrm{~m}} \mathrm{Tc}$-MIBI we were able to identify the accumulation of the drug in the projection of lymph nodes, affected by metastases, in $2(17 \%)$ of 12 patients (Figure 14). We assume, that such a low information content of SPECT with ${ }^{99 \mathrm{~m}} \mathrm{Tc}-\mathrm{MIBI}$ in the detection of metastases in regional lymph nodes is primarily related to their small size and physiological, initially high accumulation of ${ }^{99 \mathrm{~m}} \mathrm{Tc}-\mathrm{MIBI}$ in the projection of the thyroid and submandibular salivary glands, which often screens the zones of the regional lymph collector (Figure 15). This effect is less pronounced when using of ${ }^{199} \mathrm{Tl}$ (Figure 16).

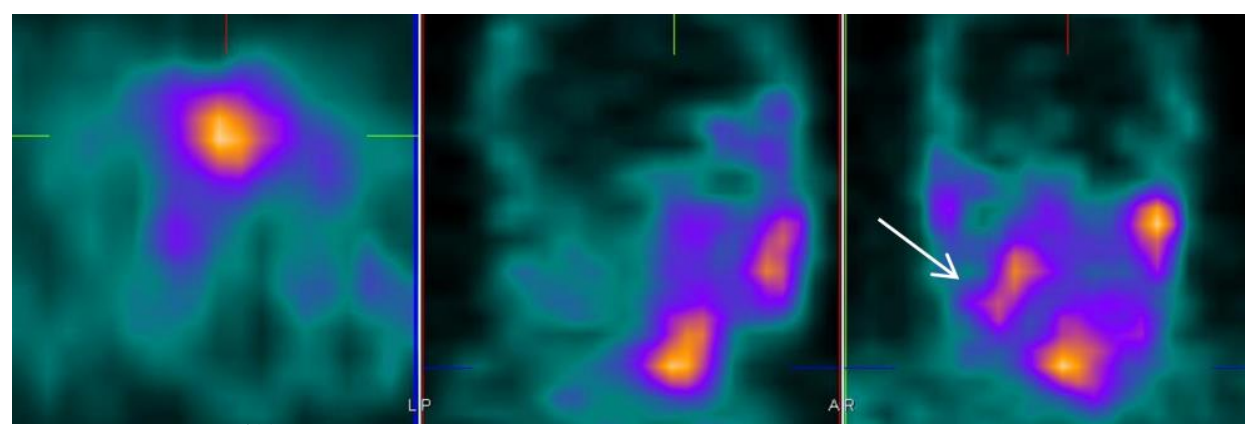

Figure 13. SPECT with ${ }^{199} \mathrm{Tl}$ for the patient with primary laryngeal cancer and cervical lymph node metastases. 

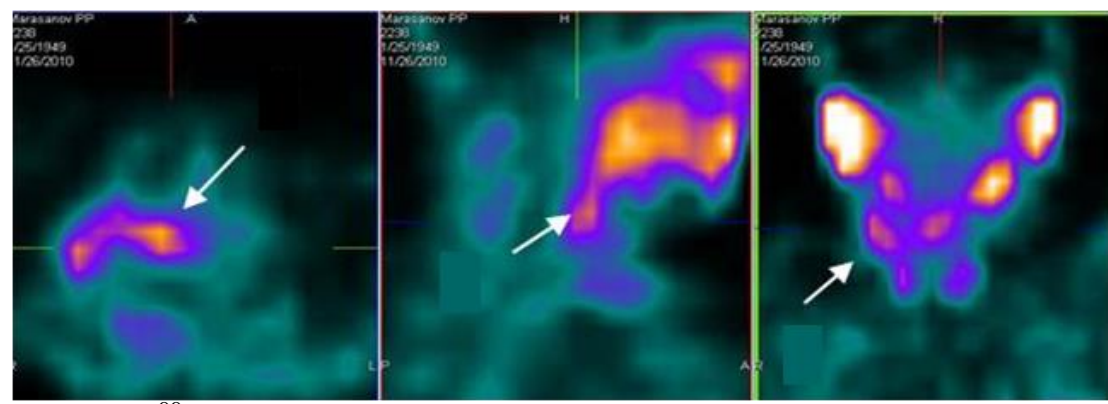

Figure 14. SPECT with ${ }^{99 \mathrm{~m}}$ Tc-MIBI for the patient with primary laryngeal cancer and cervical lymph node metastases.
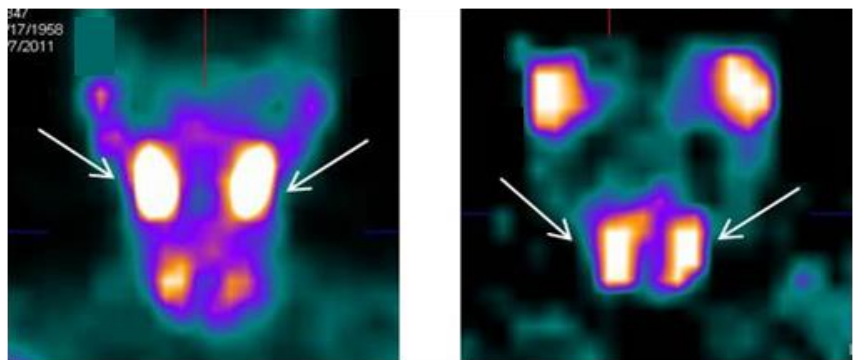

Figure 15. Screens the zones physiological accumulation of ${ }^{99 \mathrm{~m}} \mathrm{Tc}-\mathrm{MIBI}$ in the projection of the thyroid gland and submandibular salivary glands.

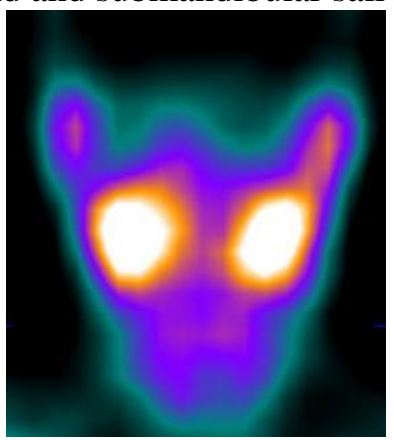

Figure 16. Physiological accumulation of ${ }^{199} \mathrm{Tl}$.

\section{Conclusion}

Our first experience of using ${ }^{199} \mathrm{Tl}$ has clearly indicated that this radiopharmaceutical represents a useful diagnostic tool for the detection of breast and laryngel/hypopharyngeal cancers. Single photon emission computed tomography with ${ }^{199} \mathrm{Tl}$ showed $100 \%$ specificity for detecting breast cancer, when compared to ${ }^{99 \mathrm{~m}} \mathrm{Tc}$ MIBI with reported specificity varying from $85 \%$ to $94 \%[5,13]$.

With regard to the assessment of regional lymph node metastasis in patients with laryngeal/hypopharyngeal cancer, ${ }^{199} \mathrm{Tl}$ SPECT demonstrated high specificity, whereas ${ }^{99 \mathrm{~m}} \mathrm{Tc}$ - MIBI failed to evaluate the status of regional lymph nodes due to its physiological high uptake in the thyroid gland.

Despite the above advantages, ${ }^{199} \mathrm{Tl}$ has also disadvantages. This cyclotron-produced radiopharmaceutical has a higher cost compared to ${ }^{99 \mathrm{~m}} \mathrm{Tc}$, the most widely used radioisotope in nuclear medicine. Moreover, our findings have demonstrated a rather low sensitivity in the detection of regional lymph node metastases in breast cancer patients, thus significantly impairing the diagnostic accuracy.

Anyway, ${ }^{199} \mathrm{Tl}$ is a promising radiopharmaceutical for the detection of malignant tumors, however, further studies are required to determine its role in the cancer diagnostic algorithm.

\section{References}

[1] A.D. Caprin, V.V. Starinskay, G.V. Petrov, "Malignant neoplasm in Russia in 2014 (morbidity and mortality)"/ M .: MNIOI P.A. Herzen - 2016. - Fig. - 250p. ISBN 978-5-85502-219-3. 
[2] A.M. Granov, L.A. Tyutin, M.S. Tolstanova, "The application of positron emission tomography with 18fluorodeoxyglucose in clinical oncology”, Problems in Oncology (Voprosy onkologii) 49, 5 (2003) 563-573.

[3] A. Aziz, R. Hashmi, Y. Ogawa, "Tc-99m - MIBI scintimammography; SPECT versus planar imaging”. J. Cancer Bioter. Radiopharm. 14 (6) (1999) 495-500.

[4] C.K. Kuhl, "MRI of the breast cancer". J. Eur. Radiol. 10 (2000) 46-58.

[5] S.J. Kim, Y.T. Bae, J.S. Lee, I.J. Kim, Y.K. Kim, "Diagnostic performances of double-phase tc-99m MIBI scintimammography in patients with indeterminate ultrasound findings: visual and quantitative analyses”. J. Ann. Nucl. Med. 21 (3) (2007) 145-150.

[6] E.L. Choynzonov, R.V. Zelchan, A.A. Titskaya, I.G. Sinilkin, S.Y. Chijevskaya, V.I. Chernov. "SPECT with ${ }^{99 \mathrm{M}}$ Tc-MIBI and ${ }^{199}$ TL-chloride in the diagnosis of primary and recurrent malignant tumors of the larynx and hypopharynx" A Century of progress in head \& neck cancer: 5th world Congress of IFHNOS \& annual meeting of the AHNS. $-2014, \quad 26-30$ july (http://ahns.jnabstracts.com/Detail.aspx?ID=56831).

[7] K. Koizumi, K. Toyama, T Araki, "Uptake of Tc-99m tetrafosmin, Tc-99m MIBI and $201 \mathrm{Tl}$ in tumour cell line", J. Nuc. Med. 37 (1996) 1551-1556.

[8] A. Sehweil, J.H. McKillop, R. Milroy, “201 Tl scintigraphy in the staging of lung cancer, breast cancer and lymphoma", Nucl. Med. Commun. 1, 4 (1990) 263-269.

[9] R.P. Spencer, “Tumour-seeking radiopharmaceuticals: nature and mechanisms”. Nuclear Medicine, 1994, No 2, P. 649-662.

[10] Yu.B. Lishmanov, V.I. Chernov, N.G. Krivonogov, "Experimental perfusion scintigraphy using ${ }^{199}$ Tlchloride, Medical Radiology and Radiation Safety”. Meditsinskaya radiologiya i radiatsionnaya bezopasnost' 3 (1988) 13-16.

[11] V. Chernov, S. Triss, V. Skuridin, Yu. Lishmanov, "Thallium-199: a new radiopharmaceutical for myocardial perfusion imaging". Int J Cardiac Imaging 1996; 12(2): 119-26.

[12] Yu.B. Lishmanov, V.I. Chernov, S.V. Triss, I.Yu. Mazurin, "Thallium-199 myocardial scintigraphy", Medicinskaa radiologia 4(1990) 35-38.

[13] A.A. Titskaya, V.I. Chernov, E.M. Slonimskaya, I.G. Sinilkin, R.V. Zelchan, "Mammoscintigraphy with 99mTs-MIBI in the diagnosis of breast cancer". Siberian Medical Journal, Tomsk. 2010. Vol. 25. № 4-1. p. 92-95. 